\title{
A humanidade do fazer musical com as Tocatas
}

\author{
The humanity of the music activity \\ within Tocatas
}

Raphael Duarte Alves Augusto ${ }^{1}$ raphael_70rocks@hotmail.com

Lucas Sielski Kinceler ${ }^{2}$ lucaskinceler@gmail.com

Leonardo Lima da Silva oitolinhas@gmail.com

Licenciado em Música, CEART- UDESC

2 Especialista em Arte no Campo, CEART - UDESC

3 Mestre em Artes Visuais, CEART - PPGAV- UDESC 


\section{Resumo}

O objetivo deste artigo é traçar a relevância social e musical do evento conhecido por "Tocata", em Florianópolis/ SC. Proposta com a forma de um encontro informal, aberto e não restrito a músicos, a Tocata se abre como uma experiência compartilhada que favorece diferentes potencialidades do fazer musical, assim como a reinvenção da relação dos participantes com a música. Dada esta especificidade das interações e do convívio humano, tal como ali ocorrem, a Tocata nos possibilita uma experiência artístico-musical que se dá no devir de um processo criativo, simultâneo e coletivo, onde a ação musical pretende se apresentar de forma afetiva, espontânea e intuitiva. Os dados da pesquisa partem dos relatos de participantes registrados entre 2015 e 2016 para - Trabalho de Conclusão de Curso: Convívio Experimental e Improvisação Musical na Tocata: da produção de uma atitude ético-estética. Situamos estes relatos em articulação com a nossa própria experiência, enquanto participantes e pesquisadores no campo da música e artes visuais, e em diálogo com estes campos introduzimos descrições da Tocata e reflexões que nos acompanham no decorrer dos últimos anos.

Palavras-chave: Tocata; Reuniões Musicais; Improvisação Musical; Processo Criativo; Colaboração; Relatos de Experiência.

\section{Abstract}

The purpose of this article is to trace the social and musical relevance of the event known as "Tocata", in Florianópolis/ SC. Proposed as an informal meeting, open and not restricted to musicians, the Tocata opens itself as a shared experience that favors different potentialities of musical making, as well as the reinvention of the relationship that participants have with music. Given this specificity of the interactions and the human conviviality, as they occur there, the Tocata allows us an artistic-musical experience that occurs in the becoming of a creative, simultaneous and collective process, where the musical action intends to present itself in an affective, spontaneous and intuitive way. The data of the research is taken from reports of participants registered between 2015 and 2016 for the Final Paper (TCC): Experimental Conviviality and Musical Improvisation in the Tocata: the production of an ethico-aesthetic attitude. We have placed these reports in articulation with our own experience, as participants and researchers in the field of music and visual arts, and in dialogue with these fields we introduce descriptions of the Tocata and reflections that have accompanied us during the last years.

Keywords: Tocata; Musical Meetings; Musical Improvisation; Creative process; Collaboration; Experience Reports. 


\section{Sobre a Tocata}

A Tocata é um encontro musical colaborativo, aberto a qualquer pessoa que queira explorar ou desenvolver sua musicalidade própria de forma experimental e informal, em conjunto com um grupo de participantes, geralmente independente de instituições de ensino e de práticas mais tradicionais de música. Não é necessário ser músico "profissional" e nem mesmo "entender" de música para participar do encontro. Portanto, o corpo de participantes da Tocata tende a ser bastante heterogêneo, formado por "não-músicos", ou seja, pessoas sem formação ou experiência com algum instrumento musical e também por músicos e instrumentistas de diversos níveis técnicos, diferentes formações culturais e graus de comprometimento com a atividade musical bem como artistas e estudantes de outras áreas.

A música produzida na Tocata se faz na medida em que o processo criativo é compartilhado no instante presente de cada encontro, sem definições e diretrizes formais, sem o auxílio de instruções ou programas previamente elaborados, sem composições, partituras, ou mesmo ensaios. Trata-se de uma improvisação musical fomentada por um grupo de participantes, os quais procuram não definir hierarquias ou funções pré- definidas para cada um. Desta forma, o grupo está sempre mudando de aspecto no decorrer da prática, já que não há necessidade nem o desejo de formar e estabilizar um grupo fechado. Sendo assim, cada participante pode, individualmente e com autonomia, escolher o momento de adentrar o espaço da Tocata, o modo como quer participar, assim como o momento de sair desse espaço. Essa situação aberta produz um intercambio contínuo de participantes bem como de referências musicais que estes agregam na improvisação, abrindo um campo sempre renovado de possibilidades criativas, de ideias e estruturas musicais singulares. Neste sentido, a forma que a música assume surge de acordos dinâmicos entre os participantes em interação, acordos que, de modo geral, se apresentam, confluem e consolidam somente no devir da prática, através da improvisação musical.

O estilo musical dessa improvisação é variável, mas de um modo bastante geral, podemos dar alguma noção das sonoridades experimentadas. É comum ouvirmos percussões - variados tipos de tambores e chocalhos, tocando junto com instrumentos melódicos e harmônicos, como por exemplo o violão, flautas, saxofone e escaleta. Além disso, ouvem-se muitas cantorias, desde solos vocais até manifestações de coro. Cada um toca a partir de suas próprias referências musicais, mas ao mesmo tempo os participantes buscam "tocar a mesma música", ou seja, a Tocata é sempre uma tentativa de reunir uma diversidade em uma unidade. Nesse sentido, e lembrando que participam tanto músicos quanto "não-músicos", é comum que a improvisação se estabilize ritmicamente através de alguma métrica regular, sugerida e reiterada pelo grupo. É frequente o uso de compassos binários e ternários, além de harmonias simples, compostas de poucos acordes e geralmente com um caráter modal, de permanência em uma determinada escala ou acorde, gerando atmosferas que possibilitam múltiplas linhas melódicas e rítmicas, solos e conversações sonoras em contínuo contraponto, compondo texturas bastante polifônicas. Esses elementos, que simplificam as possibilidades da im- 
provisação, surgem como convenções tácitas e não planejadas, e sua função parece ser a de facilitar a participação de qualquer pessoa no improviso. Quanto aos estilos musicais, eles dependem muito do grupo em questão (que geralmente muda de Tocata para Tocata). Nas Tocatas que vamos apresentar adiante percebe-se que alguns estilos são sugeridos mais regularmente que outros, como por exemplo: o baião, o blues, a música de origem africana ou afro-brasileira, o rock, a música latino-americana, especialmente a música andina. Vale lembrar que além destes não serem os únicos estilos musicais da Tocata, nenhum destes aparece completamente caracterizado, ou seja, ocorrem mesclas entre os estilos citados, bem como outros.

Atualmente na cidade de Florianópolis ocorrem (semanalmente) dois eventos musicais que se identificam com o nome "Tocata". Um deles chama-se "Tokata"1 (Fig.1), que acontece na casa do músico Polo Cabrera². O outro chama-se "Tocata Aberta" (Fig.2), proposto pelo coletivo Geodésica Cultural Itinerante ${ }^{3}$ desde 2008, e que atualmente ocorre na estrutura geodésica do campus universitário do Centro de Artes (CEART-UDESC), ou mesmo em outros locais e eventos públicos. No caso da Tokata, da casa do Polo, acontece nos sábados à noite e a Tocata Aberta, na UDESC, quintas-feiras à tarde.

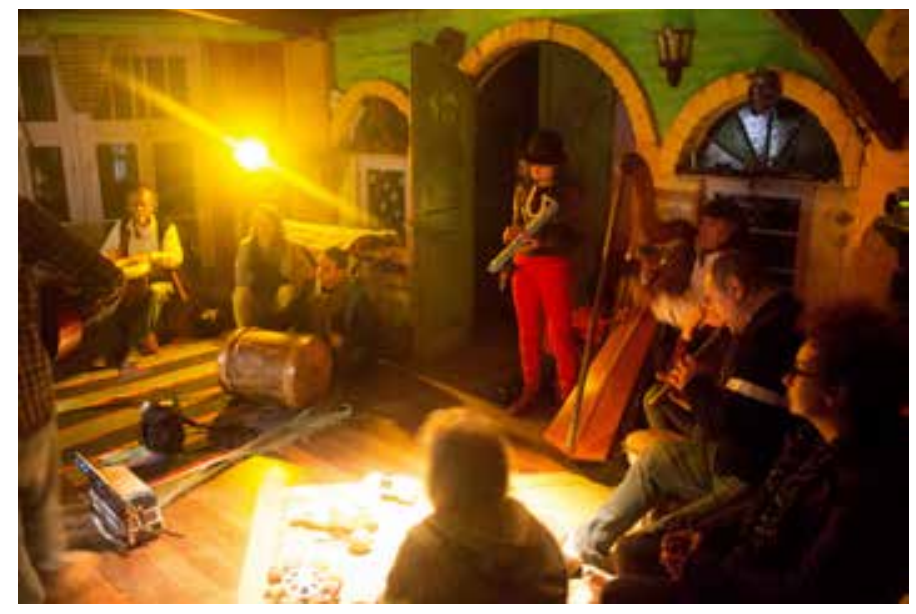

(Fig.1) Tokata na casa do Polo, 2015.

\footnotetext{
1 Tokata, com " $k$ " ao invés de "c". Um dos mais antigos organizadores dessa tocata revelou que a escrita do nome deveria ser esta. Contudo, existem outras tocatas, e a opção foi por manter o nome "Tocata" com "c" para todos os efeitos, neste trabalho, como modo de identificação geral que engloba esses dois eventos.

2 Leopoldo Cabrera Züniga, mais conhecido como Polo Cabrera, nasceu em Santiago do Chile em 28 de fevereiro de 1945. Polo é músico multi-instrumentista, contador de histórias, pintor, ilustrador, marceneiro, escritor e jornalista chileno radicado no Brasil. Saiu do Chile em meados da década de 70 com um grupo de amigos que formaram o Grupo Água, conhecido por suas composições que mesclavam diversos ritmos andinos, folclóricos e latinos em geral. No Brasil o grupo gravou com artistas expoentes da música popular brasileira como Milton Nascimento, Ney Matogrosso e Moraes Moreira. Em 1976 gravaram seu primeiro Lp, chamado "Transparência". Depois da dissolução do Grupo Água, Polo mudou-se para Florianópolis/SC na década de 1990, onde construiu sua própria casa nos arredores do bairro Porto da Lagoa. Desde então ele costuma convidar amigos e conhecidos para fazerem música em sua residência aos finais de semana, prática regular que vieram a chamar de Tokata. Para conhecer mais sobre o Grupo Água: <https://pt.wikipedia.org/wiki/Grupo_Agua>, endereço para audição online: <https://www.youtube.com/watch?v=DFh4hYBHg2I\&t=1110s> Acesso em: 20/03//2017.

3 Coletivo Geodésica Cultural Itinerante, surgiu a partir do Grupo de pesquisa "Arte e Vida nos Limites da Representação - UDESC/CNPq em 2011 e é composto por artistas e estudantes nas áreas de artes visuais, música. Atua como um dispositivo itinerante para a realização de diferentes projetos cuja base é a implementação da criatividade visando a reinvenção de relações sociais, culturais e ambientais, viabilizando espaços de convivência, experiências e saberes entre as pessoas. Maiores informações disponíveis em: <facebook.com/geodesicacultural> Acesso em: 20/03/2017.
} 


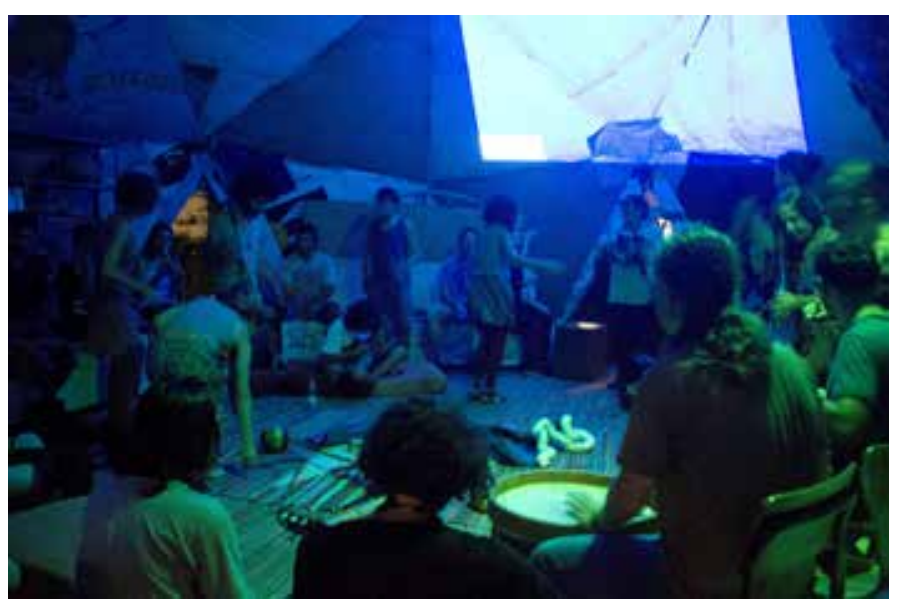

(Fig. 2) Tocata Aberta na Geodésica, CEART-UDESC", 2016.

Estas duas tocatas são eventos autônomos, porém inter-relacionados, como podemos perceber pelo uso de um nome em comum. Normalmente os participantes de uma Tocata podem vir a participar da outra e vice-versa, formando algo como um único fenômeno de improvisação musical coletiva. A Tokata da casa do Polo, contudo, acontece regularmente há mais de trinta anos no mesmo local, a partir dos anos 1990, e serviu de guia e influência para a elaboração da Tocata Aberta, que iniciou em 2008.

A Tocata Aberta, enquanto prática proposta pelo coletivo Geodésica Cultural Itinerante, surge a partir da esfera da arte pública participativa e da arte colaborativa, e tornou-se uma prática regular primeiramente por necessidade dos membros do próprio coletivo ${ }^{4}$ de gerar encontros, compartilhar e gerar saberes e processos criativos. Assim, por uma convergência de interesses e visões de mundo em comum, o fazer musical possibilitou um espaço de convívio experimental autogerido por seus próprios participantes, no qual não apenas se compartilha o processo criativo musical como também são gerados e potencializados os laços afetivos entre os participantes. A proposta era gerar um movimento em que a esfera própria da Estética (arte) pudesse complementar e se complexificar em contaminação com a esfera da Ética (convívio) para desenhar e ressaltar o caráter humanístico deste espaço-tempo experimental.

Neste sentido é importante frisar que o espaço geodésico no qual acontece a Tocata Aberta, foi criado entre os departamentos de Artes Visuais, Artes Cênicas e Música, e neste ínterim, uma de suas funções é promover um momento de integração e diálogo entre os estudantes e professores dos distintos cursos no Centro de Artes (CEART-UDESC), dos demais centros desta e de outras universidades, bem como da comunidade em geral. $O$ aspecto convivial é essencial para definir a Tocata em sua particularidade, assim como a forma específica de improvisação musical que ali se dá.

Portanto, é importante compreender a Tocata a partir da atuação do coletivo Geodésica Cultural Itinerante como uma ação que intenta reinventar o cotidiano, produ-

\footnotetext{
$4 \quad$ Membros atuais deste coletivo: Lucas Sielski Kinceler, Leonardo Lima, Raphael Duarte, Gustavo Tirelli Ponte de Sousa (mestrando em processos artísticos - UDESC), Tatiana Rosa (doutoranda em Artes Visuais - UDESC), Ágata Tomaselli (estudante de Artes Visuais- UDESC), Jade Sapucahy (estudante de Artes Visuais - UDESC, Pedro Henrique Silva (licenciado em Música - UDESC), Wilton Pedroso (Bacharel em Artes Plásticas - UDESC), Helton Patrício Matias (Bacharel e Licenciado em Artes Plásticas - UDESC), entre outros colaboradores.
} 
zindo interstícios e momentos singulares que se destaquem do fluxo contínuo da vida e permitam o contato inter-humano e a produção de subjetividade ${ }^{5}$. 0 crítico de arte Reinaldo Laddaga (1963 -) indica que convivemos hoje com a possibilidade de um novo paradigma em arte. Deste modo afirma que certos grupos de artistas:

[...] em nome da vontade de articular a produção de imagens, textos ou sons e a exploração das formas de vida em comum, renunciam à produção de obras de arte ou ao tipo de repúdio que se materializava nas realizações mais comuns das últimas vanguardas, para iniciar ou intensificar processos abertos de conversação (de improvisação) que envolvam não-artistas, durante longos períodos de tempo, em espaços definidos, onde a produção estética se associe ao desenvolvimento de organizações destinadas a modificar estados de coisas em tal ou qual espaço, e que apontem para a constituição de 'formas artificiais de vida social', modos experimentais de coexistência. (LADDAGA, 2012, p. 27 - 28) [grifos nossos]

O artista nesta perspectiva não é mais o "autor" absoluto do objeto artístico, mas sua autoria se dilui em um coletivo de participantes e a experiência pela qual eles passam juntos, passa a ser o centro das intenções artísticas. Para captar o sentido desses modos experimentais de coexistência, no caso da Tocata, é indispensável ampliar o escopo com o qual observamos o evento, de modo a não se limitar por uma descrição puramente musicológica, em seu sentido mais tradicional, cujo modelo é a análise pormenorizada e objetiva de obras musicais canônicas e seus compositores. Como em toda improvisação, a performance mesma é o único evento concreto da Tocata, não havendo nada para além do momento efêmero da criação, e para captar seus sentidos se faz indispensável contar com os relatos de experiência ${ }^{6}$, dos próprios participantes, à medida que estes buscam rememorar o modo como se comportam e sentem durante a improvisação.

Portanto, veremos que o fazer musical, estrito senso, não resume as variadas formas de atividades e ações que podem surgir durante a Tocata. Manifestações como a dança, por exemplo, ocorrem espontaneamente em conexão e sintonia com a música, não sendo de forma alguma subjugada a ela, mas ocupando o mesmo espaço-tempo de criação. O modo específico de participação pode ser, portanto, diferente, mas todos convergem para gerar o sentido vivencial da Tocata.

Deste modo percebemos a experiência proporcionada pela Tocata enquanto um "encontro humano", no sentido dado por Christopher Small (1927-2011), e conceber

\footnotetext{
5 Segundo Trecho de Suely Rolnik, (professora, psicanalista e ensaísta sobre arte e cultura) em entrevista nos diz: Não se trata de revelar nada, ela (subjetividade) tem que tomar corpo, é performatizada na nossa própria existência e esse modo de existência se transforma na criação de uma obra de arte em qualquer campo da arte que for. [...]lsso constituiu um espaço fundamental na subjetividade, que é o espaço de uma alteridade em nós mesmos. Não seria a alteridade do outro que está fora, mas seria a alteridade desse campo em que meu corpo é atravessado por essas forças, a alteridade do mundo como um campo intensivo presente na minha subjetividade - uma relação dele com meu código, meu comportamento, minha estrutura nesse código - é isso que propulsa meus devires. Faz com que eu não possa me considerar identitariamente, eu nunca sou eu mesma, porque tem sempre este outro ponto de interrogação que me empurra pra virar outra. Disponível em: <www.corpocidade. dan.ufba.br/redobra/r8/trocas-8/entrevista-suely-rolnik/> Acesso em: 10/06/2015.

6 Estamos nos embasando no termo "experiência" colocado pelo educador Larossa Bondía e que permanece pertinente: "A experiência é o que nos passa, o que nos acontece, o que nos toca. Não o que se passa, não o que acontece, ou o que toca. A cada dia se passam muitas coisas, porém, ao mesmo tempo, quase nada nos acontece." (BONDIA, 2002, p. 21). A experiência, nesta acepção, é uma paixão, sofrida por um sujeito, capaz de produzir sentido em sua vida, e assim transformá-lo.
} 
tudo o que acontece ali como fazendo parte indissociável do todo. Segundo SMALL (1998) nós devemos perceber uma performance musical enquanto um:

[...] encontro entre seres humanos que se dá através do meio sonoro organizado de maneiras específicas. Como todos os encontros humanos, ele acontece em uma conjuntura física e social, e estas, também, devem ser levadas em consideração quando perguntamos quais significados estão sendo gerados pela performance (SMALL, 1998, p. 10) 7 .

(Portanto temos aqui um complexo de relações que constituem um encontro musical. As relações entre os sons da improvisação moldam e são moldados pelas relações sociais. Nesse jogo de afetação mútua é que nos concentraremos para sinalizar a relevância social e musical da Tocata na perspectiva da experiência de seus participantes. Os relatos de experiência aqui utilizados provêm de entrevistas ${ }^{8}$ realizadas com participantes de ambas as Tocatas entre o segundo semestre de 2015 e o primeiro semestre de 2016. As entrevistas foram estruturadas segundo um roteiro proposto aos entrevistados, na seguinte cadência: descrição da Tocata; descrição do modo como se sentiam durante a improvisação musical; e terceiro, questionar se o contato com a Tocata havia produzido alguma diferença na vida musical e geral do participante. Com este roteiro, seguiremos nos próximos tópicos.

\section{Descrição da Tocata}

Para uma Tocata é necessário haver um espaço definido, por uma duração mais ou menos indefinida de tempo, pois a prática costuma encerrar somente quando os participantes decidem. No caso da Tocata Aberta, esse espaço é o domo geodésico, construído em meio ao campus da UDESC, que pretende servir enquanto espaço multiuso e laboratório de práticas transdisciplinares. No caso da Tokata da casa do Polo, o espaço é a própria casa. Ambos são espaços físicos organizados de forma a hospedar práticas artísticas e receber visitantes, criando uma ambientação lúdica, leve, meditativa, sugestiva - por exemplo, a casa do Polo, um local amplo com chão e paredes de madeira, cheia de instrumentos acústicos artesanais, esculturas e pinturas espalhadas por todos os cantos, e iluminação baixa, de cores amareladas e verdes. Do outro lado temos, para a Tocata Aberta, o domo geodésico que é em si mesmo um objeto escultórico e arquitetônico, um espaço circular e agregador. Em ambos espaços se percebe

\footnotetext{
7 Tradução livre para o texto: [...] encounter between human beings that takes place through the medium of sound organized in specific ways. Like all human encounters, it takes place in a psysical and a social setting, and those, too, have to be taken into account when we ask what meanings are being generated by a performance."

8 Como sinalizamos no resumo deste artigo, as entrevistas, como os diários de campo citados no texto, compõem o material do Trabalho de Conclusão de Curso (TCC) de um dos autores do artigo, Raphael Duarte, defendido em dezembro de 2016, sob orientação da Prof. Dra.Vania Beatriz Mûller CEART-UDESC. Metodologicamente, este trabalho obteve seus dados através das técnicas de observação participante, escrita de diário de campo e entrevistas abertas, provindas do método etnográfico.
} 
uma organização consciente de preparação do lugar para a prática social e musical que terá lugar, espalhando sofás, pufes ou cadeiras ao redor de um centro que fica vazio, ou no qual são dispostos instrumentos musicais.

Uma das características mais distintivas da Tocata é a disponibilização de instrumentos musicais para o uso e livre experimentação dos participantes. Faz parte da organização espacial do evento o esforço em tornar o conjunto de instrumentos visível e acessível, geralmente no centro de uma roda de pessoas. São instrumentos acústicos em sua grande maioria, incluindo cordofones diversos, percussões, instrumentos de sopro e de tecla, e inclusive alguns objetos e utensílios domésticos que podem ser ativados musicalmente. Os participantes podem trazer seus próprios instrumentos individuais, se os tiverem, mas o conjunto de instrumentos disponíveis na Tocata se faz público para a ocasião e pode ser utilizado por qualquer pessoa, sendo que um mesmo participante pode vir a trocar diversas vezes de instrumentos durante uma mesma Tocata, e um instrumentista não precisa necessariamente tocar o instrumento que domina, aproveitando a oportunidade para experimentar outros instrumentos. Sobre as possibilidades de timbres, destacamos dos diários de campo um trecho que narra sobre uma tocata com mais de vinte pessoas tocando simultaneamente:

O que me impressionou em certo momento foi a riqueza da instrumentação e dos timbres na tocata. Portanto quis anotar para me lembrar, o que estava sendo tocado num determinado ponto, como uma fotografia das escolhas instrumentais e das possibilidades. Estavam soando na roda: um derbak, dois djembês (depois veio mais um), dois metalofones (um pentatônico e outro diatônico), pífano, contra-baixo acústico, berimbau, maraca, dois bumbos leguero (um grande e um pequeno), a harpa paraguaia, uma "flauta grave de bambu", flauta transversa, flauta doce bem aguda, um Cuatro venezuelano, sanfona de oito baixos, uma zamponha (flauta pan), além do canto. Essa exata ordenação, na qual havia equilíbrio ao meu ver entre instrumentos de percussão e outros tipos, logo foi mudando quando alguém largou o berimbau para pegar outro instrumento e por aí foi." (Tocata na casa do Polo - 31/10/2015 - sábado à noite)

Quanto à forma do próprio evento, é importante destacar o fato de que a Tocata não é uma apresentação musical, que ela não possui a forma de um espetáculo e, portanto, não há um público ouvinte cujo único papel seja contemplar. Todos os que por ventura passam pelo espaço do evento, em qualquer ponto de sua duração, são incentivados a participar ativamente, a pegar um instrumento, a cantar e/ou dançar, acompanhando o movimento geral dos demais. A Tocata varia o número de participantes, em um mesmo evento e entre um evento e outro, pois sua forma é aberta, podendo ocorrer com cinco ou mais de trinta pessoas. As portas de entrada do local do evento se encontram abertas, subentendendo que os participantes estão livres para sair e entrar sem complicações ou constrangimentos. A Tocata, na descrição de um dos participantes, é " [...] um espaço no qual você consegue se expressar e entrar, caso você não seja músico..., e só criar aquela conexão com as pessoas no momento, sem se preocupar se tem alguém olhando, se tem alguém rindo [...]" (Riccieri Luis Paludo, 21 anos, estudante do Curso de Licenciatura em Música, UDESC).

Nessa fala surge a importância para o indivíduo de estabelecer um contato íntimo 
com o grupo de improvisadores presentes, uma "conexão", ao mesmo tempo em que ele não se preocupa em ser observado por outros, já que, de fato, não há plateia.

É um espaço de descoberta, acima de tudo. Descobrir a tua voz enquanto voz e a tua voz através do instrumento também. De explorar a linguagem [...] E acho que isso se dá por ter esse espaço que é propício, que ninguém está te avaliando por isso. Acho que essa é a maior diferença que eu vejo na prática de tocata do que em um ensaio com uma banda, que às vezes tem um fim específico. (Fala de um dos autores deste artigo, Leonardo Lima, 26 anos, em entrevista, 2016)

É a possibilidade da experimentação livre, vinculada à autodescoberta pela música, que está sendo aqui destacada e contraposta ao fato de que os participantes estão seguros de que podem explorar o fazer musical sem medo de ter que provar algo a alguém, de ser avaliado e taxado por suas habilidades. Essa situação promove, durante a improvisação, uma anulação positiva da noção de "erro" e "acerto" que acompanha a maior parte das práticas musicais baseadas na execução de peças prontas (composições). A relevância psicológica deste fato, no que concerne à qualidade musical da improvisação e da integração entre participantes, não deve ser subestimada.

Outro participante sublinha o caráter subjetivo, de "liberdade musical", vinculado a um "sentir-se à vontade":

Você está ao mesmo tempo em si, tocando e se soltando, mas conectado com os outros, sentindo o ritmo dos outros e isso vai gerando uma fluidez [...] é uma questão muito intuitiva que eu acho que até desenvolveu em mim uma questão de criatividade [...] começar a perceber o que o outro está tocando, o que você ta tocando, e sentindo isso, e se soltar mesmo, com a música. Você se sente mais à vontade de tocar sem ter um conhecimento muito grande, que eu não tenho né [...] (Ágata Tomaselli, 19 anos, estudante do Curso de Artes Visuais-UDESC, 2016)

É comum nos sentirmos pouco à vontade em qualquer contexto em que estejamos sendo "postos contra a parede", julgados ou obrigados a realizar uma ou outra atividade, o que nos impede de "relaxar". Contudo é possível gerar um espaço em que todos possam participar sem serem necessariamente obrigados a isso, e sem maiores comprometimentos, como geram os espetáculos públicos para os performers. No caso da participante citada acima, foi significativo para o desenvolvimento de sua criatividade musical que ela se sentisse confortável para experimentar e "se soltar", independentemente do fato de que sua habilidade em música não estava à altura dos "standards profissionais", e ela aponta para a estrutura não-hierárquica das relações no evento como um possível facilitador deste processo de abertura à música.

A Tocata se dá como uma continuidade musical, um fluxo, mas existem momentos de silêncio, pausas que demarcam as fronteiras de cada "episódio". Nestes episódios, a Tocata segue todo um processo de organização do material musical em tempo real, onde o percurso de cada novo impulso musical deve ser definido nos acordos que os participantes realizam de modo não-verbal, somente através do discurso sonoro: 
Então na tocata não existe começo, meio e fim, é uma continuidade infinita que às vezes não se sabe se vai ter fim. Várias vezes a gente propõe um fim pra música e quando a gente acha que chegou no fim, alguém continua tocando e não chegou no fim, ela continua e isso passaram vinte minutos naquele tema, e passaram meia hora e ela não tem fim. Então uma pessoa que tem uma estrutura musical, um conceito muito forte formado, apesar do conhecimento, não vai aceitar esse tipo de estrutura, de dramaturgia musical." (Airton Perrone, 56 anos, músico e professor, 2015)

O participante ainda coloca: "[...] tudo é muito espontâneo, sem pensar, sem organizar, nada é organizado, mas existe uma lógica mental que organiza isso naturalmente. " (idem). Como são vários participantes improvisando simultaneamente é muito comum que existam momentos de caos na Tocata, momentos em que parece não haver uma comunicação transparente entre os improvisadores. Cacofonias e defasagens inconscientes de ritmos abundam. Contudo, como está explícito na fala acima, o próprio processo de continuar improvisando parece ser capaz de organizar o material sonoro por si só e produzir acordos, harmonias imprevisíveis que são capazes de surpreender os próprios improvisadores. Ou seja, quando ocorrem momentos de sintonia e diálogo, o resultado é normalmente bastante agradável para os participantes, potencializando e incentivando a imersão dos sujeitos na atividade. Contudo, não é possível controlar nem prever o momento em que a Tocata se harmoniza dessa forma, pois a racionalidade de qualquer indivíduo não poderia conter a complexidade do devir nas improvisações de cada um do grupo. Portanto, para que haja uma sensação de fluxo perceptível na improvisação, parece ser necessário abdicar do controle sobre o processo e se "entregar" a ele tal como surge, de modo "intuitivo", como frisam diversos participantes.

E é uma coisa não informada por raciocínio, exatamente! Em geral se caracteriza por [...] sentir um momento que vem de dentro de você, de querer cantar tal nota ou talvez imitar o que você acabou de escutar outra pessoa cantando [...] é por aí a Tokata. (Jonathan Rupert Bacon Heald, 49 anos, empresário, 2016)

[...] e de uma maneira muito brincante né, não é algo: 'Ah! A gente vai parar, vai pensar, vai imaginar', não! É na hora, é sem pensar. (Elenice, 34 anos, atriz e produtora cultural, 2015)

Parece haver uma conexão entre o aspecto intuitivo do fazer musical na Tocata e o aspecto lúdico, aquilo que convida os músicos a "não se levarem tão a sério", a rirem de si mesmos quando não se encontram com o controle da situação. Longe de redundar em superficialidade, essa atitude parece cumprir um papel importantíssimo no que concerne à qualidade musical dos momentos de fluxo na Tocata.

O pessoal sabe que apesar de ser uma coisa séria, é uma brincadeira, entendeu? $E$ aí começa a chegar naquele estado em que a gente não tem mais medo de expressar, daí você pensa, vou experimentar isso, 'opa!', não ficou tão legal mas, aqui é o espaço pra isso. (Riccieri Luis Paludo, 2016)

Este é o espaço e o momento em que os ditos "erros" não assumem uma importância tão grande a ponto de serem paralisantes, o que torna o coletivo de participantes 
progressivamente mais velozes em assimilar na improvisação tudo o que vier, transformando criativamente aquilo que para eles "não soa tão bem", em algo mais interessante, pelo simples continuar improvisando.

Diversos participantes também destacaram que essa liberação da espontaneidade em grupo possui um valor terapêutico intrínseco, para além do aprendizado e desenvolvimento da musicalidade. Como na passagem seguinte:

\begin{abstract}
Já rolou comigo também de estar cansado tipo 'eu não to a fim de ir pra tocata hoje' [...] e ai quando eu to mal assim, várias vezes já rolou de eu ir mal por algum motivo e ai eu começava meio tímido assim [...] dai daqui a pouco eu 'blhaa' explodia e dai me curava! Já rolou esse lance de se curar ou esquecer, pelo menos naquele momento, que você tem que fazer 'tal coisa' e 'tal coisa' e que tem alguém que ta magoado com você ou tem isso e isso acontecendo na sua vida [...] (Pedro Henrique, 21 anos, estudante do Curso de Licenciatura em música, UDESC, 2016)
\end{abstract}

Outro participante revela o sentido de "cura" despertado pela Tocata:

[...] foi como uma nova família, um novo universo se abriu para mim, porque eu estava vindo de um momento bem difícil da minha vida, aliás, um momento que eu estava preso pra cantar, preso pra tocar, não saia som, não saia, [faz citação] 'silêncio no meu violão, nem eu mesmo sei porque' aquela história né? - e quando chegou na tocata do Polo - é: "solta a voz", "solta isso", "solta aquilo" [...] então eu comecei a "soltar" novamente, a música voltou pra mim, foi um processo de ressuscitar a música que estava parada dentro de mim. (Airton Perrone, 2015)

A conexão interpessoal entre improvisadores está diretamente relacionada ao fator terapêutico da Tocata, pois a música só pode vir à tona quando todos se percebem fazendo algo juntos. Para alguns participantes isto pode ser mais difícil do que para outros, assumir uma atitude espontânea, expressiva e "se soltar" na prática significa para cada um algo distinto. A Tocata funciona colaborativamente, quando uma pessoa que está mais segura de sua presença musical é capaz de auxiliar as demais a alcançarem o mesmo estágio, sincronizando-se com elas através de seus gestos musicais. De fato, a Tocata não ocorre espontaneamente a partir de uma reunião de pessoas, pois nem todos estão seguros de sua musicalidade a ponto de iniciarem um diálogo musical pura e simplesmente. Geralmente é necessário que algum dos participantes, familiar com o "andar" da Tocata, propicie um estimulo sonoro e uma conjuntura de tal maneira, que facilite aos demais acrescentarem seus improvisos individuais. Esse fator solidário da improvisação é perceptível particularmente no início da prática:

Mas uma coisa que é muito forte na tocata, que eu percebo que normalmente precisa de um norte, ter algum chão [...] porque alguém que vem pela primeira vez, às vezes não dá esse start, do som começar. Então, quase a maioria das vezes isso parte de alguém que já tem um contato com a tocata, que já foi algumas vezes. (Pedro Henrique, 2016) 
Então acho que a tocata é muito legal de pensar que às vezes você tem que fazer menos do que você sabe, pra dar espaço pro outro. E isso é um exercício muito grande, pra a própria questão do ego do músico, do artista, de você fazer menos pra que possa ter uma conversa. [...] Tocata tem a ver com dar oportunidade pro outro também elevar sua voz, de não ser uma competição de individualidades, de virtuosismo [...] às vezes o melhor que você pode fazer é uma nota só [...] (Leonardo Lima, 2016)

Podemos sintetizar estes pontos colocando que existe uma atitude musical e humana específica que corrobora com o processo da Tocata, levando em conta de que ela é um espaço aberto a qualquer pessoa, e que não há como prever quem participará a cada nova edição do evento, o que acrescenta risco e complexidade. Se cada um simplesmente resolvesse tocar "qualquer coisa", sem ouvir o coletivo, com toda a certeza não teríamos prazer em participar, pois não nos perceberíamos fazendo algo juntos, estabelecendo uma "conexão". Estando atentos simultaneamente à música e ao fator convívio, em uma atitude ético-estética, é possível tocar de modo "aberto" e se tornar um facilitador da Tocata. Sem facilitadores (estejam eles conscientes disso ou não) é difícil imaginar uma Tocata que flua. De fato, da perspectiva do mais antigo participante, a Tocata é definida em termos dessa ação do facilitador:

A Tokata é como facilitar um ambiente para que as pessoas venham a soltar sua
voz, ou soltar um instrumento [...]. E tem um facilitador, que nesse caso sou eu
ou outra pessoa, que vai tocando a harmonia, que nunca são muito complexas.
E é sempre uma espécie de um mantra, ou um "rondó"... são três harmonias,
máximo quatro, as vezes pode ser uma harmonia... tem que ser coisas que são
possibilitárias, não pode ser coisa muito complexa, se não as pessoas vão fican-
do fora, principalmente as que não tocam muito, que são mais inibidas. Você fa-
zendo harmonias básicas e simples para que elas possam se soltar, vai facilitando
pra ela. (Polo Cabrera, 71 anos, músico e professor, 2015)

Apesar desta ser uma improvisação bastante livre, ela possui alguns modos de ser muito regulares. Como vemos na fala acima, é importante que as harmonias e os ritmos sejam "possibilitários", que não sejam complexos demais, para que todos possam se engajar em um mesmo fazer musical. Tocar desse modo, com essa preocupação de fazer funcionar a Tocata, é o papel dos facilitadores. Contudo, nem todos tocam dessa maneira e é comum que irrompam solos musicais virtuosos e outros desafios para o fazer coletivo em algum momento. Mesmo um facilitador, como Polo Cabrera, pode complexificar bastante a música com polirritmias ou síncopes que um dado grupo não consegue acompanhar, o que leva o grupo a perder ímpeto e, eventualmente, a música pode vir a cessar. O ponto distinto e extraordinário do fluir da Tocata está, geralmente, no equilíbrio entre essas atitudes que facilitam a prática para um grupo, conectado naquele momento pelo ambiente sonoro que o produz e é produzido. Um ambiente de sonoridades e performances diversas que, uma vez apresentadas e desenvolvidas em grupo, "naturalmente" se complexificam ao gerar no exercício da repetição variações e diferenças. Isso é particular de uma descrição da música da Tocata, dentre os recursos musicais utilizados para promover tal improvisação. 
A improvisação musical, de acordo com BAILEY (1993, p.12), pode ser idiomática, quando toda a invenção ocorre a partir de um gênero ou "idioma" musical específico, presentes na música popular (nas vertentes norte-americanas do jazz, blues; do rock, sobretudo ao final dos anos 60; das cantorias do samba-de-partido alto; do repentismo; de tradição latino-americana (a exemplo da música andina); de tradição Oriental (como a Indiana e Chinesa); ou até mesmo tonalismo, modalismo, etc.). Ou uma improvisação não-idiomática, quando não se detém em nenhum idioma em específico, como o que geralmente se chama Livre Improvisação'. Contudo, na Tocata, observamos uma improvisação um tanto quanto híbrida. Todos os estilos e culturas musicais familiares aos participantes podem fazer parte do improviso, inclusive, esse é um modo de permitir que todos participem do improviso "jogando com aquilo que tem nas mãos". Ao mesmo tempo, e pelo mesmo motivo, nenhum idioma particular é estabilizado definitivamente, havendo sempre em andamento uma trajetória musical e cultural que nos leva de um estilo ao outro. Muitas vezes é um instrumento que define o modo de tocá-lo e, assim, o estilo ou gênero musical (atabaques costumam soar "africanos", charangos costumam soar "andinos"). "Então a grande arte da tocata é o improvisar em cima de uma mesma coisa. Então aí que entra o 'menos é muito', o 'menos é mais' [...]" (Airton Perrone, 2016). Para ilustrar melhor estes aspectos musicais da improvisação, apresentamos outro trecho do diário de campo:

Não consigo me lembrar de tudo o que ocorreu na tocata em termos de música, mas, de início eu ouvia a harmonia de um tom "menor", infinitamente repetida e bem estabelecida pelos instrumentos de corda (violões, viola, etc), mas também pela tendência das vozes a melodizar sobre esta mesma harmonia. Com um ritmo constante, às vezes "batendo" mais no chão, marcando os tempos fortes, ou ao contrário, sincopando muito. As "influências musicais" pareciam vir da mescla entre tradições ameríndias, árabe e africana, além da europeia. Ouvia-se a todo o momento essa mescla "transcultural", no estilo dos cantos, nos próprios instrumentos e timbres escolhidos, nas diversas maneiras de tocar, nas melodias instrumentais. Havia gente tocando sobre uma escala pentatônica e, ao mesmo tempo, havia algum instrumento (como um metalofone) afinado em uma escala heptatônica, além de eventuais cromatismos e notas dissonantes nas linhas de alguns instrumentos (como na flauta transversa e nas cordas pinçadas). Havia sempre uma métrica mais ou menos definida subjacente a toda a massa sonora, mas uma métrica frágil e dinâmica, que às vezes, em questão de

9 A Livre Improvisação também é marcadamente distinta da improvisação na Tocata, apesar de manter semelhanças com ela. Segundo BAILEY (1993, p. 83) a Livre Improvisação (Free Improvisation) não se compromete com idioma algum - o que é similar à Tocata de certo modo pois ela também não se compromete com nenhum idioma específico, mas permite uma variedade destes. A Improvisação Livre surgiu como um movimento mais ou menos coeso a partir dos anos sessenta (idem, p. 84) e foi motivada pela vontade de romper com a linguagem musical tradicional. Rogério Costa (2003, p. 16) define que a Livre Improvisação objetiva ser o "avesso de um sistema" : "Numa prática deste tipo perseguimos estes objetivos através da variação contínua e da permanente desterritorialização das constantes que configuram os sistemas. $E$, mesmo que durante este processo surjam novas distinções e sistemas, trabalhamos no sentido de dissolvê-las passo a passo na performance." (COSTA, 2003, p. 16). Diferentemente, na Tocata não se almeja uma variação contínua dessa forma, de modo a não caracterizar, metodicamente, nenhum idioma. Pelo contrário, "joga-se com o que se tem", e todos os idiomas (ou alguma mescla de idiomas) podem ser caracterizados, dependendo somente dos participantes em questão e dos acordos musicais que eles efetuam entre si durante a prática. Portanto, a sonoridade de uma Tocata, apesar de que sua improvisação é bastante livre aos ouvidos de seus próprios participantes, difere radicalmente da sonoridade da Livre Improvisação, que parece estar mais comprometida (musicalmente) com as noções de "ruptura" provenientes das vanguardas do século XX, o que também podemos chamar de "estética da sonoridade" (GUIGE, 2008). A presença, nem sempre constante, de pulsações regulares e harmonias modais determina em parte a sonoridade da improvisação da Tocata. 
segundos, tornava-se mais forte e mais marcada ou, ao contrário, mais nebulosa e desencontrada. Os ritmos variavam entre um toque mais "indígena" por parte das percussões (tambores e principalmente maracas), com marcação regular do tempo forte em 4 por 4 (TCHÁ - tcha - tcha - tcha - TCHÁ - tcha - tcha - tcha - TCHÁ.. ou: TCHÁ - TCHÁ - TCHÁ - TCHÁ... etc.), e um toque mais "africano", também reforçado principalmente pela percussão (atabaques, alfaias, pandeiro, etc.), com ritmos irregulares e altamente sincopados, contando com a presença de polirritmias mais ou menos aparentes. O caráter das melodias vocais também era dinâmico (dependendo muito do cantor e do contexto). Às vezes todos tocam algo que é muito familiar para a maioria, e daí conseguimos uma coesão maior, mas muitas vezes ocorrem dissociações nas quais um pequeno sub-grupo (por exemplo: três pessoas sentadas uma do lado da outra) faz uma referência bem clara e marcada a um determinado estilo ou ritmo, com um nome e identidade definida, como "samba" por exemplo, enquanto outros grupos, ou a maioria, não faz nenhuma referência mais clara nesse sentido. A mistura geral disso tudo é a regra, observada em diversos momentos e durante todo o andamento da Tocata. (Tocata na casa do Polo - 29/07/2015 - sábado à noite.)

Ao ser questionado sobre o porquê dessa diversidade de estilos e idiomas musicais na Tocata, de onde vem essas referências todas, Polo Cabrera declarou:

\begin{abstract}
Vem do 'sopão do inconsciente coletivo'. Por isso que às vezes na Tokata aparecem ritmos nunca conhecidos, aparecem ritmos africanos, ritmos da Irlanda [...] por uma forma, se parece [...] Então a gente mexe na Tokata com o inconsciente coletivo, com esse sopão do inconsciente, então tu pega ritmos que tu nunca escutou, ou pega coisas que se parecem com outra coisa [...] não tem uma definição de estilo, de cultura a Tokata. Ela é múltipla, alguma vez parece com um tipo de coisa, depende muito dos instrumentos que você vai usar. (Polo Cabrera, 2015)
\end{abstract}

Existe algo na própria natureza da música improvisada, sendo ela somente o momento mesmo da performance, que parece permitir tal mescla, tais confusões e multiplicidades, sem constrangimento algum. É próprio dos fenômenos acústicos individuais que eles durem pouco e logo morram, desaparecendo no mesmo silêncio do qual vieram - não são como objetos visuais, com contornos definidos, mas processos vivos que existem no espaço-tempo. Essa condição sonora da efemeridade, em cada evento particular, potencializa a capacidade do improviso de moldar e plasmar a matéria sonora, e lhe dá ímpeto, velocidade no processo contínuo de criação. Desse modo, todos os "erros", sonoridades estranhas e não desejáveis, passam, e imediatamente temos a possibilidade de transformar o caminho da improvisação, tomando desvios ligeiros e explorando outras possibilidades. Por outro lado, tudo aquilo que nos surpreende na Tocata como sendo excepcionalmente harmonioso, belo, profundo, tem data de validade muito curta e desaparece sem deixar vestígio assim que deixamos de tocar. Essa situação propiciada pelo improviso musical quase que nos obriga a concentrar a atenção somente no momento presente, no que está sendo feito aqui e agora. Para tanto é necessário uma certa dose de desapego. O entrevistado Airton Perrone (2015) conclui em sua fala: 
[...] não pode pensar que aquilo ali que você tocar você vai depois anotar, que vai lembrar e fazer uma música. Não, aquilo tem que ter consciência que está indo pro universo, por mais lindo que seja, foi. Cada tocata é um disco que sai e já era, foi para o universo." (Airton Perrone, 2016)

\section{Durante a Improvisação}

Uma das questões que os entrevistados tiveram de responder diz respeito a descrição de seus estados internos, suas sensações, percepções e sentimentos em meio ao processo de improvisar. Durante as experiências nas Tocatas foi possivel notar que este improviso se desenvolvia dinamicamente, que sua qualidade se alterava conforme os eventos sucediam, e que isto estava diretamente conectado com o estado psicológico dos indivíduos. Em certos momentos o ato de improvisar poderia parecer maçante e até artificial. Em outros momentos (de uma mesma continuidade musical) esse quadro se alterava drasticamente e era possível sentir que improvisar era algo fácil e natural, espontâneo, que as ideias pareciam fluir por si mesmas, o que ocasionava um imenso prazer. Esse é o fazer "intuitivo" que vários participantes descrevem ao verbalizar suas experiências. Descrevemos este estado de consciência na passagem em que o entrevistado comenta sobre o que lhe fez aproximar da música e seu processo de improvisação: "[...] é uma espécie de leveza e uma espécie também de sair de si, sair do momento. É como se você entrasse num outro espaço, completamente diferente do que você está no momento, e nele mergulhar." (Leonardo Lima, 2016)

Outros participantes indicam uma semelhança entre este estado de consciência musical e o estado provocado pela meditação:

[...] na Tokata você está concentrado para que a linha melódica que está saindo de ti esteja sempre te surpreendendo, então, se você está prestando atenção nisso já é um estado de meditação, ou seja, o foco atencional é teu canto e o que tá saindo de dentro dele. Ao mesmo tempo você tem outro foco, que é você estar escutando as pessoas cantando, e você chega a sentir uma vibração de prazer no ar, aí a Tokata se eleva [...] agora, a Tokata você tem que entrar dentro dela. Se você fica observando de fora, é como observar as crianças fazendo Tokata, aí você começa a analisar as imperfeições. Se você está dentro da Tokata, você entra a tocar, a participar, você entra num êxtase, entra no êxtase da Tokata [...] produz um prazer imenso a Tokata. (Polo Cabrera, 2015)

Talvez seja oportuno agora colocar que alguns termos foram muito mais recorrentes do que outros na fala dos entrevistados. Dos doze entrevistados, seis mencionaram a categoria "liberdade" para descrever a Tocata e o modo como se sentiam nela; também seis vezes surgiu a categoria "conexão". Mas o termo mais recorrente foi "fluir", ou "fluxo", aparecendo sete vezes.

". Mas o termo mais recorrente foi "fluir", ou "fluxo", aparecendo sete vezes. Destacar isso é importante porque estes termos parecem estar todos correlacionados com o modo como os participantes se sentem durante a improvisação. A sensação de fluxo é um indício de que a improvisação musical está funcionando no nível individual psicoló- 
gico de cada sujeito, o que produz uma concentração distinta na música, e uma fruição que a acompanha.

O psicólogo Mihaly Csikszentmihaly (1934 -) realizou uma pesquisa na qual questiona o que é uma experiência ótima (optimal experience). Quando, como e porque nos sentimos tão bem em determinadas circunstâncias, e porque isso não ocorre sempre? No intuito de esclarecer tais questionamentos a pesquisa de Csikszentmihalyi (2008) reuniu relatos pessoais de sujeitos provenientes de várias partes do mundo: esportistas, artistas, pessoas comuns, jovens, velhos, etc. Flow ("fluxo", enquanto substantivo, ou "fluir", enquanto verbo) é o modo como essas pessoas, de modo geral, descreveram seus estados internos (psicológicos, mentais) enquanto realizavam atividades que elas fruíam (enjoyed) em particular.

Dentre as descrições mais comuns da "experiência ótima" encontramos apontamentos tais como o "esquecimento de si" (do self, ou do conceito do "Eu"), uma sensação alterada da temporalidade, uma concentração tão intensa que não sobra nenhuma atenção para pensar sobre outras coisas, entre outras características. Todas essas características são apontadas por um ou outro participante da Tocata, ao descreverem esses momentos em que a improvisação parece estar fluindo excepcionalmente bem.

Quando estamos em "fluxo" estamos concentrados apenas na atividade presente e nada mais. Mesmo que essa atividade nos dê ganhos que estão para além dela mesma ("objetivos externos"), projetados no futuro (como dinheiro, mais habilidades ou prestígio), a sensação de fruição é intrínseca ao que fazemos no presente. É a atividade por ela mesma, enquanto é realizada, que se experimenta como sendo particularmente prazerosa, pois é no presente que nosso estado mental se harmoniza em ação: "'Fluir' é o modo que as pessoas descrevem seu estado mental quando a consciência é harmonicamente ordenada, e elas querem perseguir seja o que for que estejam fazendo em si mesmo." (CSIKSZENTMIHALYI, 2008, p. 6) ${ }^{10}$.

Contudo, de acordo com Csikszentmihaly (2008), A experiência chamada flow tende a ocorrer em um ponto ideal quando as habilidades (skills) exercidas por uma pessoa estão à altura, e combinam, com o grau do desafio (challenges) oferecido pela atividade em questão. Quando estas condições estão presentes, é necessário que a nossa atenção, considerada como a "energia psíquica" da consciência, se volte com exclusividade para a atividade presente, que está demandando tal engajamento por parte do indivíduo. Quando os desafios são muito elevados a pessoa pode sentir angústia e estresse, e quando são pouco elevados (relativamente às habilidades disponíveis), o que segue é a monotonia. Como esta experiência é subjetiva, só podemos constatar sua existência através dos relatos de experiência que cada sujeito faz sobre seus próprios estados internos.

Como a Tocata é aberta para que o participante se integre no improviso no modo como quiser, independentemente de seu nível técnico, é possível que diversas pessoas, com habilidades distintas, encontrem no evento um espaço que os desafie o suficiente

10 Tradução livre para: "'Flow' is the way people describe their state of mind when conciousness is harmoniously ordered, and they want to pursue whatever they are doing for its own sake." (CSIKSZENTMIHALYI, 2008, p. 6) [grifo nosso]. 
para concentrarem-se e entrarem em fluxo. Para cada um existe um desafio distinto, mas o interessante é que é possível que muitas pessoas de diferentes níveis de experiência musical possam encontrar um espaço para entrar em fluxo junto com os demais. Portanto, na Tocata é possível que este fluxo, psicológico e individual, possa ser compartilhado e, não só, mas também gerado colaborativamente, quando todos se percebem "fazendo algo juntos":

É uma experiência muito subjetiva, a tocata, para cada um é diferente. O que eu sinto é uma coisa que se aproxima do que muitas pessoas falam, da improvisação te levar num estado de espírito que te permite a entrar numa área desconhecida. É uma relação muito direta com as pessoas, você está numa roda então é muito corporal [...] o mais importante pra mim é de você estar praticando música com outras pessoas, que é muito diferente de quando você está sozinho em casa, por exemplo, não que você não possa atingir um estado de espírito, mas eu acho que ali facilita porque é muito mais palpável, [...] é uma troca de energia [...] é difícil explicar isso pra quem não participa mas você sente a energia, "a coisa" se materializa, aquela energia se materializa pela música. [...] Você se contamina pela energia do outro e vai gerando uma coisa que é uma coisa só, ao mesmo tempo. (Leonardo Lima, 2016)

Nesta fala a sensação "meditativa", "intuitiva", de "perda si" que o fluxo traz, está ligada diretamente à troca de energias com o coletivo, a "conexão". Portanto temos aqui um processo paralelo que ocorre simultaneamente nas mentes individuais, mas que depende da percepção de que os demais também estão neste mesmo processo de fluxo. Quando o processo do fluxo é compartilhado a Tocata se expande e algo destacado ocorre, como uma erupção de energia, que "sobe", "explode" e se dissipa. Uma Catarse.

Uma catarse acontece quando todo mundo chega num ponto ápice, que está tocando, que essas vozes entram em harmonia e provocam harmônicos. Então esses harmônicos são os resultados de várias vozes cantando, acordes, intervalos de terça, de quinta, de sétima, inconscientemente, mas chega num momento que isso acontece, e ritmicamente também. Então isso provoca uma catarse. Então esse momento que a gente diz que a tocata que ela "gira", e acontece esse fenômeno que é o fenômeno da catarse, que é o "de arrepiar na tocata". Por alguns segundos isso acontece e depois se desfaz novamente. (Airton Perrone, 2015)

\section{O que mudou depois da Tocata?}

A última questão que cada entrevistado respondia dizia respeito à relevância dessa experiência em sua vida pessoal e musical: mudou alguma coisa para você, antes e depois da Tocata? - As respostas inicialmente foram unânimes, todos responderam que a prática fez uma diferença marcante em suas trajetórias individuais.

I. Com certeza, com certeza. [...] Foi tipo uma virada né, uma relação quase nula com a música, de "fazer música", por assim dizer, por não se sentir à vontade, e agora foi de zero a não sei quantos por cento. É de querer, essa vontade que eu nunca imaginei ter, de cantar, soltar voz, nossa eu preciso ir lá. (Ágata Tomaselli, 2016) 
II. Até então eu improvisava, improvisava, mas depois da tocata, aí esse improvisar criou outras coisas além das simples escalas de improvisar. Quer dizer, o improvisar ele é muito relativo. Quer dizer, o jazz ele é uma coisa muito relativa. Uma tocata pode ser super jazz. [...] então ela tem esse aspecto de te abrir pra outras fontes de improviso que não são as fontes tradicionais. (Airton Perrone, 2015)

III. E aí, depois que eu comecei a participar, meio que virou uma [...] parece que está sempre em processo criativo, todo o sábado você entra num processo criativo. E às vezes quem lida muito com a arte, assim, se distancia muito do processo criativo [...] (Elenice, 2015)

IV. "Sim, Sim", Porque eu tenho me conectado com essa capacidade de fazer música que não está escrita, que não está só formalizada, antes que você toca ela. Então você está atingindo alguma coisa ao vivo, uma coisa que não nasceu ainda, então isso é poderoso [...] abriu muito o campo para mim. (Jonathan Rupert, 2016)

V. Ah! mudou,! [...] mudou muito a minha relação com os instrumentos. Acho que na primeira vez que eu toquei a escaleta 'meu deus, preciso de uma escaleta pra mim!', fui lá e comprei uma escaleta, daí depois a flauta, 'meu deus!' [...] (Mariana, 18 anos, estudante do Curso de História - UDESC, 2016)

VI. Sim, claro. [...] O que eu percebi é que em ambientes, que não são como a Tocata, eu consigo fazer música agora. Consigo sentir a minha 'curva de aprendizado' de instrumentos, de timbres [...] é como se fosse aberto um novo leque de escutar música, você escuta mais coisas agora. (João Ricardo Lázaro, 23 anos, estudante do Curso de Artes Visuais - UDESC, 2016)

VII. Ah! Eu acho que sim cara, isso é bem claro, assim, todo mundo que começa a improvisar e fazer parte da Tocata, os depoimentos gerais são: 'nossa, depois do Polo a minha vida mudou'. E é real porque ele te estimula, vai liberando os "nozinhos" que a gente tem assim no peito, na garganta, na voz e tal, de pegar uns instrumentos e tentar fazer o som sair dali. (Pedro Henrique, 2016)

VIII. Não só musical, não é mesmo? Pessoal, espiritual, tudinho, sério. Minha relação com as pessoas também mudou completamente [...] eu não conhecia quase ninguém do coletivo (se refere tanto ao coletivo Geodésica Cultural quanto ao grupo das Tocatas na UDESC) assim, quando eu chegava (Geodésica-UDESC) já me sentia tão em casa que já começava a deixar fluir, por mais que eu não conhecesse o pessoal que tava ali. (Sofia Bach, 19 anos, estudante do Curso de Artes Cênicas - UDESC, 2016) 
IX. Com certeza. [...] você começa a se familiarizar com um tipo de relação com a música, então, a partir do momento que você gera um hábito ou associa a música com uma coisa muito mais coletiva, muito mais dissolvida no encontro, e quando você vê ela confinada, separada, acaba sendo cada vez mais difícil de aceitá-la desta forma. (Leonardo Lima, 2016)

Como podemos observar, as mudanças percebidas nos indicam uma pluralidade de efeitos positivos na vida dos participantes, tanto no desenvolvimento musical quanto de caráter terapêutico, e, sobretudo, no modo de se relacionar com outras pessoas ao fazer música. A partir destes relatos, sintetizaríamos que a singularidade da Tocata é possibilitar uma outra relação com a música, um outro modo de se comportar diante de um fazer musical coletivo, dos instrumentos, e uma outra forma de organizar a prática musical, que não é a forma tradicionalmente colocada pelas instituições de música ocidentais. Sendo estas os ambientes destinados à prática e ensino de música, ou seja, escolas e modelos de ensino, incluso a própria universidade, bem como os distintos locais onde a música é "exposta" e "consumida", como tantos outros.

De modo geral, no que se refere ao propósito deste artigo, compreendemos que tais locais são historicamente pautados, sejam as atividades de formação, ensino, prática e fruir musical, no aprendizado compartimentado e individual, ao domínio técnico de um instrumento, à leitura de partitura, onde a música é criada e geralmente reservada e preparada aos ambientes de apresentações e espetáculos, alguns destes, públicos, mas não totalmente acessíveis. Pontuamos não de maneira a refutar esta forma, dos caminhos formais e institucionalizados para os estudos teóricos e práticos do saber e fazer musical, os quais historicamente ofereceram e ainda oferecem nítidas contribuições. Contudo, sugerimos atenção para o tipo específico de sujeito que é produzido nestes ambientes, ou seja: o músico enquanto expert ou artista-gênio, intangível para tantos e cada vez mais distante de compor relações mais perenes com os contextos sociais e culturais, "do mundo comum", em que habita; e do espectador, que justamente para ser diferenciado dos que fazem música, na imagem que descrevemos acima, é paulatinamente colocado, quando não restringe a si mesmo, em uma condição passiva de ouvinte, a um grau muito baixo de participação e contribuição para o saber e fazer musical.

Estas últimas questões, que certamente caberiam ser melhor detalhadas e aprofundadas, contribuem para nos ajudar a compreender a emergência da Tocata enquanto um processo criativo que pretende ser compartilhado horizontalmente, de proporcionar um estar subjetivo que se dá no coletivo, no sentido de não somente reunir pessoas em torno de algo, mas um coletivo que habita e é habitado por este processo criativo. É uma celebração da música que parece ter um fim em si mesma, no instante em que é produzida.

\section{Considerações}

Com as Tocatas, portanto, analisamos um ambiente propício a esse tipo de aprendizado informal da música, uma possibilidade para que as pessoas possam se iniciar em um instrumento e na prática de tocar em grupo. São encontros musicais nos quais o 
fazer musical está entrelaçado à vivência em coletivo, às questões propriamente éticas, como a de "dar espaço" ao outro, "saber ouvir", dialogar, enquanto indivíduo e enquanto grupo, das pessoas presentes na ocasião. A improvisação é uma das ferramentas que catalisa todo esse processo. Neste sentido a Tocata apresenta uma possibilidade para a improvisação musical sendo a mais aberta possível, permitindo que o processo criativo da música seja compartilhado e fruído por qualquer um.

No entanto, observamos ser indispensável que haja uma facilitação da prática, que pelo menos alguns dos participantes toquem de modo "aberto", permitindo que, àqueles presentes no espaço-tempo da Tocata, entrem em sincronia e harmonizem-se, segundo seus próprios parâmetros. Deste modo compreendemos o contexto gerado pelas Tocatas altamente favorável ao aprendizado da música, à medida que torna os participantes não-músicos progressivamente mais autônomos e confiantes em participar de atividades musicais, a cantarem e experimentarem instrumentos musicais diversos.

Através de sua vivência, a Tocata promove o empoderamento musical de pessoas com ou sem qualquer iniciação musical com a voz e outros instrumentos, ao colocar em contato primordial com a musicalidade própria de cada um, transparecer a confiança de poder criar algo. Entendemos que a musicalidade não é um dom especial de alguns indivíduos privilegiados, mas que faz parte de um saber indissociável de nossa condição humana, enquanto sujeito e humanidade, podendo ser ativado e desenvolvido, ou mesmo atrofiado, simplesmente por desuso.

Infelizmente, em nossa sociedade, o fazer musical criativo (oposto ao reprodutivo) não é devidamente incentivado. Temos mais acesso do que nunca à música, pela via das tecnologias de informação, contudo, paradoxalmente, fazemos cada vez menos música. A música se tornou ao mesmo tempo banal, por excesso; ainda assim, continua rara, ou seja, este excesso, em si, não é capaz de converter maiores possibilidades de um fazer musical informal, de maior autonomia. Refém de parâmetros a que somos submetidos (e replicamos) culturalmente, vemos o músico na imagem de alguém excepcionalmente diferente dos demais, e com esta predisposição, muitos de nós são desencorajados a explorar e desenvolver a "musicalidade interna", como coloca um dos entrevistados (Airton Perrone, 2015).

Fazer música, assim acreditamos, é uma atividade importante e muito significativa para aquele que a realiza. Quando nos limitamos a somente ouvir obras completas, ao que foi composto e realizado por outros em distintos contextos e temporalidades históricas, por vezes esquecemos o cultivo de um outro tipo de relação, que se desenvolve no fazer de nossa própria música, especialmente em grupo, sendo este um estado de tamanha importância, de entrar em ação (e "conexão") através da música, já que ação "é tudo o que ela é". Como bem coloca Small (1998):

A natureza e o significado fundamental da música não estão em objetos, não estão em obras de música de forma alguma, mas na ação, naquilo que as pessoas fazem. É apenas pela compreensão do que as pessoas fazem quando elas tomam parte em um ato musical que nós podemos esperar compreender sua natureza e a função que ela cumpre na vida humana. Seja o que for esta função, eu estou 
certo, primeiro, que tomar parte em um ato musical é de central importância para a nossa própria humanidade, tão importante quando tomar parte no ato da fala, ao qual se assemelha (mas do qual também difere em pontos importantes), e segundo, que todos, qualquer ser humano normalmente capacitado, nasce com o dom da música não menos do que com o dom da fala. Se o caso é este, então nossa vida diária atual de concerto, seja "clássico" ou "popular", na qual os poucos "talentosos" são empoderados para produzir música para a maioria de "não-talentosos", é baseada em uma falsidade. Isso significa que os nossos poderes de fazer música por nós mesmos foram tomados de nós, e a maioria das pessoas tiveram roubada a musicalidade que é delas por direito de nascimento, enquanto algumas poucas estrelas, e aqueles que as gerenciam, crescem ricos e famosos por vender-nos aquilo que nós fomos levados a acreditar que nos falta. (SMALL, 1998, p. 8)

A importância da prática da Tocata é inegável no contexto em que vivemos, onde a vida cotidiana tem o seu tempo preenchido por fazeres pragmáticos, os quais nem sempre correspondem às atividades em que podemos exercer nosso potencial criativo, seja para nosso prazer e aprendizado pessoal, seja para compartilhar nossos saberes em espaços sociais. E o tempo "livre", oportuno para nos dedicarmos a tais atividades, é reduzido a atividades individuais ou sociais, que chamamos de lazer. em grande parte mediadas e permeadas por relações de consumo, de maneira que vemos nosso tempo diário escapar com as possibilidades de gerar experiências subjetivas transformadoras, de cultivar amizades e realizar coisas pelo "simples prazer" de realizá-las. Além de empoderar as pessoas ao fazer musical, a Tocata é, em si mesmo, um modelo possível de convívio experimental, onde é possível vivenciar em primeira mão certas relações sociais que estão ali sendo celebradas. A própria organização dos participantes em círculo indica que todos estão voltados para todos e que não há uma hierarquia pré-definida. A função do facilitador indica o caráter coletivista da prática, da importância social de abarcar a todos na atividade, de incentivar, de permitir, de abrir e de não fechar. Uma posição que pretende construir uma situação igualitária entre os presentes, para que música a ser produzida gere significados para todos.

Neste sentido a improvisação livre gera um espaço onde as singularidades individuais passam a se manifestar, a ser respeitadas e incluídas. Cada um pode contribuir com o que tem no momento em que achar oportuno, por "livre e espontânea vontade". Tudo o que "sair" está, automaticamente, dentro da Tocata, nada é excluído, seja "belo" ou "feio", "caótico" ou "ordenado". O importante é a capacidade do coletivo de buscar uma solução satisfatória para as situações que surgem em tempo real, estabelecendo acordos musicais, explorando a efemeridade dos sons para tomar desvios repentinos, se

\footnotetext{
11 Tradução livre do texto original: "The fundamental nature and meaning of music lie not in objects, not in musical works at all, but in action, in what people do. It is only by understanding what people do as they take part in a musical act that we can hope to understand its nature and the function it fulfills in human life. Whatever that function may be, I am certain, first, that to take part in a music act is of central importance to our very humanness, as important as taking part in the act of speech, which it so resembles (but from which it also differs in important ways), and second, that everyone, every normally endowed human being, is born with the gift of music no less than with the gift of speech. If that is so, then our present-day concert life, whether "classical" or "popular", in which the "talented" few are empowered to produce music for the "untalented" majority, is based on a falsehood. It means that our powers of making music for ourselves have been hijacked and the majority of people robbed of the musicality that is theirs by right of birth, while a few stars, and their handlers, grow rich and famous through selling us what we have been led to believe we lack." (SMALL, 1998, p. 8)
} 
for o caso, ou sustentar uma harmonia, criando uma nova situação mais representativa de um "fazer juntos" no qual todos se encontrem representados.

Participar dessas relações é modelar o convívio criativamente, do modo como desejaríamos que fosse. Finalmente, podemos nos questionar sobre a abertura que a Tocata promove para a participação de todos em uma improvisação livre. Como isso seria possível? É legitimo perguntar. Quando todos os envolvidos em uma performance seguem um programa definido, que indica o que cada um deve fazer no momento exato, surgem dificuldades nos momentos de ensaio, porém, quando o ensaio termina, temos uma peça pronta e soando relativamente bem - o programa é uma garantia de sucesso ao mesmo tempo que é uma formalização e uma organização do fazer. Mas, em uma improvisação sem qualquer roteiro, não há qualquer garantia de nada, não temos aqui a figura do compositor, do indivíduo que produz a partitura, o programa a ser seguido. Alguns participantes podem ser músicos melhores do que outros (no sentido de estarem "familiarizados com algo" do que simplesmente critérios estéticos), mas isso não impede que a prática redunde em um grande caos amorfo. A situação da improvisação coletiva é mais complexa do que a da não improvisação. Compreendendo acrescentar a estas considerações, trazemos uma nota sobre "o crescimento da complexidade em um sistema" nas linhas do filósofo francês Edgar Morin (1921 -) que bem condiz com o que queremos tocar aqui:

Há uma ambigüidade de luta, de resistência, de colaboração, de antagonismo e de complementaridade necessária à complexidade organizacional. Coloca-se então o problema de excesso de complexidade que, em definitivo, é desestruturante. Pode dizer-se grosseiramente que quanto mais uma organização é complexa, mais tolera a desordem. Isto dá-lhe uma vitalidade porque os indivíduos [elementos do sistema] estão aptos a tomar uma iniciativa para regular este ou aquele problema sem ter que passar pela hierarquia central. É uma maneira mais inteligente de responder a certos desafios do mundo exterior. Mas um excesso de complexidade é em definitivo desestruturante. No limite, uma organização que só tivesse liberdades e muito pouca ordem, desintegrar-se-ia a menos que houvesse como complemento dessa liberdade uma solidariedade profunda entre seus membros. A solidariedade vivida é a única coisa que permite o aumento da complexidade. (MORIN, 1991, p. 113 - 114)

Neste sentido, o excesso de complexidade está no risco, em não termos mais o controle sobre os resultados, pois quem está definindo a música é a subjetividade de cada um, com e a partir do outro. Temos muitas subjetividades, possibilidades e imprevisibilidades, e encontramos um terreno ainda mais fértil em ambientes que possibilitem, a partir do encontro, dilatações e contrações das singularidades de cada um, no estar e no vir-a-ser social. Como fazer da Tocata um espaço-tempo criativo de sons, de uma complexidade que não redunde em caos, cacofonia e frustração, mas que proporcione harmonias imprevisíveis e estados de fluxo prazerosos? A resposta deve ser procurada nessas relações humanas que conformam o modo de convívio experimental, a atitude ético-estética que buscamos tocar. 


\section{Referências}

MORIN, Edgar. Introdução ao pensamento complexo. Lisboa: Instituto Piaget, 1991.

LADDAGA, Reinaldo. Estética da emergência: a formação de outra cultura das artes. Tradução de: Magda Lopes. São Paulo: Martins Fontes - Selo Martins, 2012.

SMALL, Cristopher. Musicking: the meanings of performing and listening. Middletown: Wesleyan University Press, 1998.

BONDIA. Jorge Larossa. Notas sobre a experiência e o saber de experiência. Revista Brasileira de Educação. № 19. 2002.

CSIKSZENTMIHALYI, Mihaly. Flow: the psychology of optimal experience. New York: Harperperennial Modernclassics, 2008.

BAILEY, Derek. Improvisation: Its nature and practice in music. Da Capo press, inc: United States of America, 1993.

GREEN, Lucy. How popular musicians learn: a way ahead for music education. Farnham, Surrey: Ashgate Publishing Company, 2002. 